\title{
INSTRUCTIONS TO CONTRIBUTORS
}

Behaviour Change is a quarterly journal devoted to the publication of research involving the application of behavioural and cognitive-behavioural principles and techniques to the assessment and treatment of health, social, organisational, community and educational problems. It publishes original empirical studies using either single subject or group comparison methodologies, review articles, case studies, brief technical and clinical notes, invited book reviews, and special issues dealing with particular topics in depth.

\section{MANUSCRIPTS SHOULD BE SUBMITTED TO: \\ Professor Alan Hudson, \\ Department of Psychology and Intellectual Disability Studies, \\ RMIT, \\ PO Box 71, \\ Bundoora VIC 3083, Australia.}

\section{Preparation of manuscripts}

Four copies of each manuscript, prepared according to the Publication Manual of the American Psychological Association, 4th edition (1994) should be sent to the editor with a cover letter requesting review of the manuscript. Spelling should conform to the Macquarie Dictionary. The cover letter should contain a statement indicating that the manuscript has not been published elsewhere nor is it currently under editorial review.

\section{Cover page}

The manuscript must have a cover page with the title of the article, author(s) names and affiliation, a running head and at the bottom of the paper the name and postal address of the person to whom correspondence, proofs and reprint requests should be sent. To facilitate anonymous review the second page should include the title of the article without author identification.

\section{Abstract}

Articles should be accompanied by an abstract which should not exceed 200 words. The abstract should follow the title page on a separate page. It should provide a brief overview of the aims, method and major findings and should not refer to the body of the text in the abstract.

\section{Typing}

Manuscripts should be typed on A4, double spaced, with $4 \mathrm{~cm}$ wide margins. If a manuscript is accepted for publication authors who have prepared the manuscript on an IBM-compatible PC or Macintosh computer should submit a copy of the paper on disk in addition to the final hard copy version. Acceptable word processing formats are: Word Perfect (up to version 5.1), Microsoft Word (up to version 6), Multimate, Wordstar, Office Writer, Microsoft Works, Macwrite, and ASCII. Disks may be supplied in either 3.5 inch or 5.25 inch formats. The word processing program used and version number are to be specified in writing on the title page of the final accepted manuscript.

4. Tables and Figures

Tables require consecutive numbering and should be referenced by number in the text. Tables should be typed on separate sheets. Indicate in the text the approximate location of tables and figures.

\section{Proofs and Reprints}

Page proofs will be sent to the corresponding author for correction. Excessive alteration of the manuscript, as distinct from correction of errors in reproduction are not permitted and will be charged to the author(s). Authors will receive 25 copies of their paper free of charge. Additional reprints may be ordered when the proofs are returned. 


\section{CONTENTS}

The Effect of Short-term Food Deprivation on the Reinforcing Value of Coffee in Bulimic and Control Women

Cynthia M. Bulik, Emma C. Brinded, Rachel H. Lawson

Kia Marama: A Cognitive-Behavioural Program

for Incarcerated Child Molesters

Stephen M. Hudson, William L. Marshall, Tony Ward, Peter W. Johnston and Robin L. Jones

Cognitive-Behavioural Treatment of Bulimia Nervosa

Harold Leitenberg

What is a Psychological Unit?

Vicki L. Lee

Empowering Families: Policy, Training, and Research Issues in Promoting Family Mental Health in Australia

Matthew R Sanders and Sarah B Duncan

Book Reviews 